\title{
Otium cum dignitate
}

\author{
Hans Heinrich Brunner
}

Reto Steiner tritt in den Ruhestand. Ich benutze diese Gelegenheit, um dem langjährigen Weggefährten einen freundschaftlichen Gruss zu entbieten.

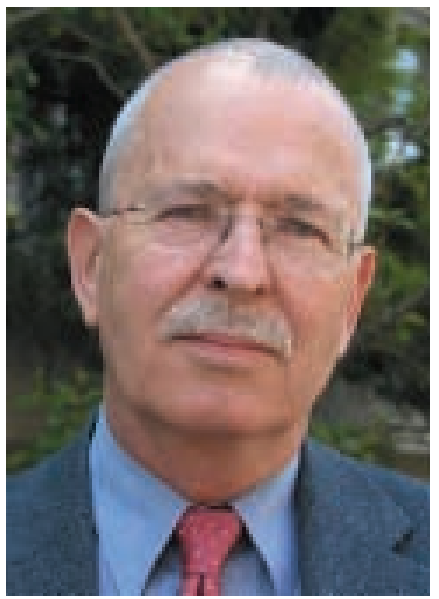

Reto Steiner
Als Reto Steiner 1986 zur FMH stiess, konnte er schon auf eine beachtliche berufliche Anamnese zurückblicken: 1969 Eintritt als Journalist bei Radio DRS, zuerst im damaligen Ressort «Unpolitisches», dann Übertritt ins Ressort Inland, anschliessend Bundeshausredaktor; von 1977 bis 1981 Deutschlandkorrespondent des Schweizer Radios mit Sitz in Bonn, nach der Rückkehr Inlandredaktor, anschliessend Chef des Ressorts Nachrichten und Journale.

Viele erinnern sich heute noch an die unverwechselbare Stimme von Reto Steiner, die Gefäss für packende, differenzierte Kommentare war.

Nach den vielen Jahren als Redaktor der «Schweizerischen Ärztezeitung» übernahm er 1998 die Aufgabe des Pressesprechers und Kommunikationsbeauftragten der FMH, eine Tätigkeit, die alle seine Kenntnisse und Erfahrungen gleichsam in ein abschliessendes Feuerwerk zusammenfassten.
Pressesprecher und FMH-Präsident stehen in einem engen Verhältnis, das, soll es erfolgreich sein, von Offenheit, Loyalität und darauf aufbauender Freundschaft gekennzeichnet sein muss. Dieses subtile Vertrauensverhältnis kann und muss auch die Möglichkeit beinhalten, Kritik an den Präsidenten auszuüben. Diese Kritik wusste Reto Steiner stets höflich und bestimmt, nie aber verletzend anzubringen.

Legendär ist seine freundliche Diplomatie, mit der er noch das aggressivste Mitglied auf den Boden sachlicher Rationalität zurückzuholen wusste. Diese Eigenschaft machte ihn zur «aussenpolitischen Drehscheibe» der FMH, die mancher schätzte und zu benutzen wusste. Dabei wusste er wie wenige, dass erfolgreiche Berufspolitik sich nach der Maxime «suaviter in modo fortiter in re» - und nicht umgekehrt - zu richten hatte.

Reto Steiner hat sein «otium cum dignitate» verdient, das er aber wohl mit Arbeit in anderem Kontext zu nutzen weiss. Die FMH verliert einen kultivierten, intelligenten, kenntnisreichen, der Sache der FMH verpflichteten Mann; es ist ihr zu wünschen, dass sie solche Leute wieder gewinnen kann. 